from 12 to 15 cents. Edison will soon give a public exhibition of his new invention."

So much for the New York Sun. Although a student of science will have little difficulty in associating the results promised with the discovery of perpetual motion, it is quite probable that Mr. Edison has actually succeeded in doing what he states he has done in his tele. gram: "I have just solved the problem of the sub-division of the electric light indefinitely." What we wish to point out is that it is one thing to do this and another thing to produce an electric light for ordinary house and street use. Once put the molecules of solid carbon in motion, and just because a solid is in question, the light must be excessive and the expenditure of energy must be considerable.

While it is easy to believe that the future may produce a means of illumination mid-way between the electric light and gas, it is equally easy to see that the thing is impossible without great waste, and therefore cost, with dynamo-electric machines and carbon poles. So long as carbon is employed we shall have much light which, perhaps, can be increased and steadied if various gases and pressures are tried. But streets and rooms full of such suns as these would be unbearable unless we sacrifice much of the light after we have got it. Split up the currrent in the manner so cheerfully described by the New York paper, and the carbon will refuse to flow altogether if an engine of 5,000,000 horse-power be employed instead of the modest one of 500 which is to light the south part of the island. If Mr. Edison has succeeded in replacing carbon he may have turned the flank of the difficulty to a certain extent.

Although, however, we may pity the ignorance of those who act upon such statements as those made by the imaginative New York Sun, gas companies may well begin to feel uneasy at the general attention wbich is being drawn to the electric light as a substitute for gas if they are prepared to let things alone. That in one form or other it is likely to be partially adopted in all large cities and at extensive public works seems most likely. It will be one of the lights of the future, but not to the excluding or superseding of gas-light.

Our own columns have repeatedly borne testimony to the success which has attended its introduction into Paris, where it is to be met with at almost every corner, and at one or more of the railway stations. The general testimony of those who are unprejudiced is that at least for wide streets, squares, and open places, its lighting effect is all that could be desired. Every Londoner is familiar with the effect of the display which the enterprising $\mathrm{Mr}$. Hollingshead has placed in front of the Gaiety Theatre, and the glowing contrast presented to the miserable yellow flames of the neighbouring street-lamps; but this contrast exists because the gas is bad and dear. Mr. Hollingshead, in a letter to the Daily News, corrects the view of the gas companies, that the electric light must necessarily cost more to produce than gas. His own display, necessarily wasteful, costs four-fifths what gas would, and he is probably correct in saying that with proper management it need not cost more than one half. Moreover, in yesterday's Times, Mr. E. J. Reed refers to the case of M. E. Manchon, a large manufacturer at Rouen, who has gone to considerable expense to alter his premises to suit the electric light, and who, even with hired engine power, finds that there is an annual saving of 22.6 per cent. over gas, with infinitely better light and a wholesome atmosphere. Mr. Reed is of opinion that even if the electric light cost more than gas, its advantages are so great, that for the lighting of public places, museums, art galleries, manufactories, \&c., he would advocate its general introduction. Even Madrid, one of the most backward cities in Europe, has introduced the light, one great benefit of which, especially in theatres and other much frequented places, is that the heat generated and the contamination of the air is greatly less than in the case of gas.

Let the directors of gas companies do all they can to improve their gas. They may be certain that it will never cease to be required; a considerable splitting up of the electric current is impossible, while the brilliant light that we shall always get when electricity is employed will gradually so raise the pitch of illumination that more gas than ever will be used.

\section{THE MEDICAL FACULTIES}

$\mathrm{THE}$ opening addresses of the various London medical schools always form an interesting episode in the scientific year, and this session they have been even more interesting and have attracted more attention than usual. This is especially the case with the vigorous and trenchant address (published in full in the British Medical Journal of October 5) of Prof. Ray Lankester. On another page we reprint a remarkable article from the Lancet, in which it is plainly stated that without endowment of research the progress of medicine must soon become impossible in this country; that the work of scientific investigation demands practically the whole energies of a competent man and is incompatible with the necessity of earning a living in any other direction. It is somewhat remarkable that such an article should be published simultaneously with the outspoken address of Prof. Lankester, who aimed to show that the great Universities of this country are faithless to their duty and to the end for which they were established, in not providing for the pursuit of scientific research, in so far at least as that bears on the healing art.

"The work of the medical profession-its function in the community" -he showed, "is to bring into practical use an inmense mass of accurate knowledge with regard to the conditions affecting the healthy working of the human body. Accordingly, two distinct kinds of activity-one dependent on the other, one as important as the otherare to be recognised as essential to the business of the medical profession. The one consists in the accumulating of knowledge relating to the human body and to the conditions affecting its health, the sifting of 'false from true knowledge, the producing of new knowledge; the other consists in the application of this knowledge to particular cases of disease or danger in such a way that action may be taken, avoiding the disease or danger, or alleviating the suffering which results from them.

"There is a most mischievous notion current at the present time," Mr. Lankester went on, "that the first of these lines of work is 'theoretical,' and that the second is 'practical;' and it is not unusual to separate the 'theoretical' from the 'practical' man, 
and to speak of the "theoretical" and the "practical" portion of medical studies. "Such a division," Mr. Lankester truly said, "is a relic from the bad old times. Theory and practice in medicine, as elsewhere, go hand in hand. The results of scientific investigation cannot be applied in the treatment of disease by the man untrained in scientific method any more than the delicate tools of a lathe can be used by one who has not himself devised them, or a watch be mended by the aid of a treatise on watch-making."

Mr. Lankester pointed out that in the present unsatisfactory state of the multitude of medical faculties in England, dependent on the voluntary services of busy medical practitioners, medical education must necessarily be defective; and that so far as this is concerned, the wealthy Universities of Oxford and Cambridge have for long most shamefully neglected their duty. As a result of this neglect on the part of our universities, medical education in the last century was a thing almost unknown in England. Those who were desirous of qualifying themselves for carrying on the profession with anything like thoroughness, had to go to Scotland, or Paris, or Italy, where the idea of a university with its various "faculties," has all along been kept in view. The multitude, however, were content with a simple "apprenticeship" to a medical practitioner, while a few latterly took to following the hospital physician round the wards, to take note of the "great man's" receipts. "But as for instruction in physics, in chemistry, in comparative anatomy, in physiology, in the general properties and activities of living things, it had no existence in London, and was not in any way required on the part of the licensing bodies. The English universities meanwhile, which possessed rich endowments for carrying on these studies, allowed jobbery and indifference to convert their ancient medical officer into sinecures." It was from Scotland, where the torch of true university life was kept burning, that an impulse towards the establishment of better things in benighted England came and set men to work in London. The origin of University College was then referred to, it being pointed out that Government, in its caprice, denied the privilege of granting degrees to the rigorous young institution, and conferred it upon a shadowy body, to which it misapplied the title of London "University," a mere nominis umbra, and an utter misapplication of the venerable term. However well the London University may have carried out its anomalous duty, we share in Prof. Lankester's profound regret, that the grand old title of "University" should have been in this way completely divorced from the work of study and teaching. The result is that, in this country, not one man in a hundred, even amongst those possessing university degrees, knows what a university is. "The Universities of Oxford and Cambridge, on the one hand, have entirely departed from the old standard, and ought long since to have been checked in their career and reformed by the power which chartered and protected them in their early days; whilst the admirable body which we call the University of London has precisely the same claim to be called a university as has the Archbishop of Canterbury."

Prof. Lankester then went on to show on how wide a basis of scientific investigation and study the medical ar ought to be built; it is the outcome, the final result, of observation.

"This is the spirit," he said, "in which the great universities of Europe, with the exception of Oxford and Cambridge, have fostered the study of medicine. This is the explanation of the existence of chairs of Chemistry, of Physics, of Botany, and of Zoology, in all their Medical Faculties. Such is the nature of his work that the medical man needs instruction and training in all the great branches of physical science; and from time to time the methods of investigation, the modes of speculation and the generalisations with which he has become familiar in the course of these apparently remote studies, render him most efficient service in the attempt to ascertain and to deal with diseased states of the human body. It is thus that a thorough knowledge of the organisation of both plants and animals becomes part of the equipment required by a medical man, but it is even more directly that the progress of knowledge relative to other organisms affects knowledge relative to the human organism. The knowledge of diseased and of healthy conditions of all organisms, all knowledge of living things, inciuding necessarily man himself, forms one compact interwoven body of science termed biology, and upon this directly the medical art is built, in it all medical practice has its foundation."

But in order that the results of scientific research may be applied to the alleviation of human suffering, there must be continued investigation in order to produce new knowledge. "The production of new knowledge," $\mathrm{Mr}$. Lankester justly said, "is a most absorbing and arduous business. Men who have anything else to do except a small amount of teaching can do very little-only a bit here and there-in the production of new knowledge. Men who are earning their livelibood in the practice if a profession can do very little at it. Men who are preparing students for examination all day all the year round can do but little at it. Only men with fortunes, or men who are paid by the institutions especially founded and meant for the production of new knowledge, can be expected to do much in this way. The institutions especially founded and designed for this production of new knowledge, and richly supported by large annual grants of money in the form salaries and stipends, are abundant on the Continent of Europe; they are the Universities. In London we have no such institution; there is no University of London in this sense of the word. The medical profession in England, though it has eleven "Faculties" in London and other "Faculties" in provincial towns, is almost totally deroid of those splendid opportunities for profound investigation-for the production of new know ledge bearing on medicine-which the appropriation of public money and ancient endowments to the paynent of the Medical Faculties in Germany, for instance, provides."

It is certainly, as Mr. Lankester said, at first sight rather astonishing that we laborious, hard-headed Englishmen, the countrymen of Harvey and Darwin, shuuld have to go to Germany for so much of our new knowledge, and that our text-books of science, instead of being provided by the richly-endowed Fellows of Oxford and Cambridge, should to a large extent bear on their 1 tlepages the names of German professors. This sur $_{\mathrm{i}}$ rise 
ceases when we are told that the German university system, consisting of twenty-one universities and $\mathrm{I}, 250$ salaried professors, is carried on at an annual expense of nore than $600,000 l$ " At the least, half of that sum and half of the number of salaried workers are devoted to the branches of science connected with medicine. "How is it we have nothing of the kind in England? Is it impossible?" Theanswerts, in Mr. Lankester's words, that "the production of new linowledge cannot go on without the assistance of endowments or their equivalent. It is impossible to name a single case of a man who did not enjoy either a private fortine or an endowment, and yet has added greatly to scientific knowledge. Medicine and the scienees which she protects have most urgent need of endowment for the purpose of supporting men who shall chiefly occupy themselves in the production of new knowledge:" Mr. Lankester's words will show how things are managed in Germany :-

"It is a disgrace to English civilisation that a true university - an endowed university, a university in which new knowledge is continually being produced, and in which men are trained for this work of production as the work of their lives-does not exist in London and in each one of our large cities. I can briefly tell you some of the circumstances which have prevented the foundation of such desirable institutions in this country; and $I$ will further indicate to you what we may hope to see done in this direction in the future. But first let me give you a sketch of one of these German universities which we so much admire and envy. I advisedly select one situated in a small town-the University of Heidelberg. Heidelberg is one of the two universities of the Grand Duchy of Baden, Freiburg being the other; whilst at Carlsruhe, in the same state, is an important technical school. The town of Heidelberg numbers but 22,300 inhabitants. The university has $6 \mathrm{I}$ professors, and, by the last returns, 834 students. Of these, 23 professors and Ior students belong to the faculty of medicine. The government of Baden, by which the salaries of the professors are paid and their number determined, does not consider that this proportion of one professor to every five students is an excessive proportion on the side of the professorial staff. 'This university was founded nearly five hundred years ago (in I386), and, like all the German universities, was remodelled and greatly improved at the beginning of this century, whilst since that time its wants have continually been provided for with ever-increasing liberality by the state government. There are now four faculties-that of Theology, that of Law, that of Medicine, and that of Philosophy. The professors are divided into the ordinary and the extraordinary. The ordinary professors receive a stipend of about $400 \%$ yearly, besides their fees, which in some cases bring their incomes up to $x, 000 \%$. When a vacancy occurs in a professorship the state minister invites the members of the faculty in which the vacancy has occurred to name two or more individuals whom they would recommend for appointment. The faculty meets and the name of a professor in some other university is proposed. $\mathrm{He}$ is written to and asked whether he will come; he probably replies that he would require an increased salary and a new Jaboratory; very usually his terms are agreed to by the state minister on the recommendation of the faculty, and he is installed in the vacant chair. Sometimes, of course, a younger and less known man is appointed at a lower salary. As an example of the way in which these things are managed in Germany, let me give you an actual history of what recently occurred at Strassburg. I quote from an American journal. 'After the transfer of that city to Germany neither pains nor money was spared to make the university a success.
For the chairs of the medical faculty rising men were selected, all of whom were known for original research, and had practically proved their ability as teachers and writers. The chair of pathological anatomy was given to von Recklinghausen, one of the most brilliant of Virchow's pupils, who vacated a similar position at Würzburg in order to accept this new position. When the chair of pathological anatomy at Vienna became vacant by the retirement of the veteran Rokitansky it was offered to von Recklinghausen, and the salary proposed was 25,000 francs ( $1,000 \%$.), or about three times the usual salary of such a professorship. But the Prussian government was quite as anxious to retain Prof. von Recklinghausen as the Austrian government was to obtain him, and asked him to say what he wanted. His reply was to demand, as the condition on which he would remain, that there should be constructed a large pathological institute, in accordance with his plans, and in connection with the hospital-an institute which will cost something like $50,000 l$., and will require a change in the fortifications. His demand was acceded to, and he is hard at work now in Strassburg." "

Prof. Lankester then describes the magnificent arrangement in Heidelberg for carrying on all kinds of research by men whose great business is to add to new knowledge, with the minimum of destruction of any kind. Here, among other well-known names, Bunsen, "the most eminent of living chemists," and Kühne, the physiologist, the author of the text-book as well known in England as in Germany, have their laboratories and class-rooms; and Gegenbaur is the head of the anatomical institute.

Other names equally great in original research in the various departments of science and other towns in Germany could be mentioned. "Berlin possesses laboratories and museums on a palatial scale, and a perfect army of investigators and students supported by State endowments. Leipzig, again, Strassburg, and Munich, are larger and more richly provided than Heidelberg. All the twenty-one German universities, the eleven Austrian, the four Swiss, and six or more Russian universities (I do not speak of those in Scandinavia, France, Holland, Belgium, and Italy), are fitted out in the same way. In all, medicine is being advanced and developed by the never-ceasing production of new knowledge."

"We, in England," as Mr. Lankester goes on to say, "benefit by this knowledge; we, in common with the rest of mankind, reap the rewards won by the activity of these noble corporations; and yet, it is neither more nor less than the fact that we Englishmen do not possess, throughout the length and breadth of our land, a single institution of our own where such work is done." In the three or four institutions where anything like original research is carried on in this country, the endowments are so inadequate as to seriously hinder anything like complete and satisfactory work. "To speak of these institutions as taking the place in this country of the vast machinery and resources of the Medical Faculties of Germany would be about as reasonable as to compare the pleasure-boats on the Lake of Geneva with the British navy."

Prof. Lankester then sketches the state of things which have come to exist at Oxford and Cambridge. These Universities were founded for the purpose of giving education in medicine as well as in theology, and endowment after endowment was made by men anxious that the Universities should fulfil their functions with efficiency; 
but through intrigue these magnificent endowments have been almost entirely filched from the purposes for which they were meant, and the property which was thus consigned to the tender mercies of the Church, is now estimated to produce yearly in each University over 300,000 .

"For many years the faculties of law and medicine struggled on in Oxford, growing weaker and more neglected in each decade, until now, after 200 years of this usurpation, there is not a single medical student in the place. In Cambridge the story was very much the same, excepting that there the degradation of the medical faculty has never proceeded quite so far as it has at Oxford, and medical studies are now, we have some reason to hope, being resuscitated in that university by the strenuous efforts of Prof. Humphry and Dr. Michael Foster." We take a few instances from Mr. Lankester's address:-At Oxford, shortly before the destruction of its character as a university, the King, Henry the Eighth, had founded a Regius Professorship of Medicine. The office still exists, and is worth about $500 \%$ a year, but the present tenant of the office gives no lectures and has no pupils. Linacre, the founder of the College of Physicians of London, Mr. Lankester tells us, "left to Merton College in Oxford (in the reign of Henry the Eighth) a piece of land, the rental of which was to pay a lecturer in medicine. Within 100 years the office was abolished, and the money converted to the private uses of the Fellows of the College. Confiding benefactors came forward last century and put down their money, in the hopes of promoting medical study in Oxford. But they did not know-and at the present day you cannot make people believe-how shameless and unprincipled were the bodies to whom they entrusted their money. Lord Lichfield bequeathed $200 \%$. a year for the reading of clinical lectures in the Radcliffe Infirmary to the students in medicine of the University. The office is now held by the Regius Professor of Medicine, but no lectures are given. About the same time, Matthew Lee confided money to the care of the governing body of the cathedral house of Christ Church, for the payment of a teacher of human anatomy, and to buy subjects for his demonstrations, but no such teaching is given; the money is applied to other purposes. Dr. George Aldrich, in 1798 , left $9,000 \%$. for 'similar purposes, but, at the present day, the bequest bears no fruit for the benefit of medicine."

These are only a few instances of the scandals connected with the history and present condition of our great universities, mainly owing to their complete subjection to clerical influence. The colleges, instead of being lodginghouses for poor students, as they were intended to be, were converted into boarding-schools, into which the Fellows received the sons of the landed gentry and wealthy citizens as pupils, on condition of certain payments. To quote Prof. Lankester:-

"The fees demanded by the College-Fellows increased at last to such an extent, and the expense of residing in one of these boarding-houses became so great, that the universities entirely ceased to be popular or national institutions in function, though they were so in foundation. They became the exclusive possession of the clergy and the wealthy classes, and so they remain at the present day. Long ago, students ceased to seek the lecture-rooms of Oxford and Cambridge for the purpose of serious study or professional training. Whilst the Scotch farmer's lad can earn enough in the fields during summer to keep him during a winter's session in the University of Glasgow or Edinburgh, whilst all classes of the community contribute to form the student-world of the German Universities, Oxford and Cambridge, under the influence of clerical domination, have become simply 'finishing. schools for young gentlemen' (I quote the words of Prof. Max Muiller). Men of moderate means-that is to say, the majority of our fellow-countrymen-now: only go to Oxford or to Cambridge with the view of sharing in the scholarships and fellowships, which are annually distributed there by competitive examination. In their whole tenour, purpose, and being, these places are as different as they possibly can be from their quondam sisters the universities of Germany:"

What Prof. Lankester insists upon is the establishment of a fully-developed and amply-endowed Medical Faculty in both Cambridge and in Oxford, and, still further, the establishment of one or two such faculties in London. We are glad to think that there is an immediate prospect of a great development of the Medical Faculty at Cambridge, where already experimental physiology, human anotomy, and clinical medicine are taught and prosecuted with energy. There is indeed some prospect that in the course of years, when men with a better spirit have sway in both universities, they: will be brought to fulfil all the functions for which they were originally established; and we trust that Prof. Lankester's address may act as the little leaven in the minds of all who heard or may read it, and that gradually not only professional men but the constituencies generally will wake up to a realisation of the -immense benefits which are the nation's birthright, but from the enjoyment of which it has for so long been barred.

Prof. Lankester then urges that one, or at most two, medical faculties should be established under the University of London.

"In this way," he concludes, "we might have in London, each provided with ample laboratory, museum, and assistants, two professors of physiology, one of surgical anatomy, one of comparatire anatomy, one of embryology, one of botany, one of pathological anatomy, one of pharmacology, one of hygiene, one of forensic medicine, two of chemistry, one of experimental physics, and others of the history and practice of medicine, of surgery, of midwifery, and of psychiatry. The maintenance of such a staff, with their laboratories and assistants, would require an endowment of $20,000 \%$ a year, whilst $100, \infty 00 l$. would have to be sunk in providing the necessary buildings. This proposition appears Utopian, but all I have to say further in defence of it is this, that in Berlin, Vienna, Leipzig, and other continental cities the thing is done, and on a more costly scale than I have here suggested.

"When such medical faculties as I have sketched to you exist in Oxford and in London, England will have begun to do her duty by the great profession of medicine. Until then we are but hangers-on of foreign nations; until then we reap where we did not sow, we gather where we did not straw. Until that time I earnestly beg every man who enters on a medical career to remember that he is joining the cause of a profession deprived of its heritage, and to make it his business to reinstate medicine in her seat, and to secure the restitution of her possessions."

Prof. Lankester is not only Professor of Zoology at University College, but a Fellow of Exeter College, Oxford: so that he speaks with full knowledge, and 
not as an outsider, who might be accused of ignorance and of interested motives. The subject which he has thus brought prominently into notice concerns the highest welfare of this country and the place which she holds among the cultured nations of the world.

\section{MILLER'S CHEMISTRY}

Elements of Chemistry, Theoretical and Practical. By William Allen Miller, M.D., LL.D. Revised by Charles E. Groves. Part II. Inorganic Chemistry. (London: Longmans and Co., 1878.)

THE number of editions through which this part of the late Dr. Miller's work has passed and the high position it has attained as a Text-book of Inorganic Chemistry render the work of the reviewer almost superfluous, and we have now only to notice what improvements or additions may have been made in the present edition.

The revision of the volume just published has been entrusted to Mr. C. E. Groves, whose position as subeditor of the Chemical Society's Journal renders him particularly fitted for this work, by reason of his being constantly brought into contact with communications upon the more recent discoveries in the science.

The order in which the various elements and their compounds are discussed, as we are told in the preface, rcmains the same as in the last edition, this order commencing with the least complex compounds and finishing with those of a more complicated nature. Hydrogen is first studied as the standard of atomic weights, densities of gases, \&c., and as affording a good example of an electro-positive element; it is followed by the monatomic but electro-negative element chlorine, subsequently by oxygen as illustrating the diatomic condition, boron illustrating the triatomic, carbon the tetratomic, nitrogen the pentatomic, and sulphur the hexatomic. We have thus presented to us in the first chapters of the work the consideration of seven typical elements and their compounds, which tends to give the reader in a simple manner a general idea of the scientific arrangement of the other elements which follow them in their respective groups.

We rather regret that $\mathrm{Mr}$. Groves has thought it necessary to retain boron in its position as the typical element of the triatomic group to the exclusion of nitrogen, taking that latter substance as the illustration of the pentatomic group. Our reasons for saying so are, that boron is not so well known to the student as nitrogen, nor does it possess a hydrogen compound like ammonia ; its atomicity, therefore, must be shown by its chlorine compound, thus destroying the similarity with the other types, which in the first four groups are illustrated by their compounds with hydrogen. Had nitrogen been taken as the type of triatomic bodies, phosphorus would then of course have replaced it as the example of a pentatomic element. Farther, by taking nitrogen as the type of pentads, as is done in Chapter $x$, a little confusion, we think, is liable to be produced in the mind of the beginner; as immediatcly after the consideration of that body as a pentad, he proceeds to consider ammonia where nitrogen is not pentatomic but triatomic.

Many of the more recently-discovered non-metallic compounds have been added to the work, and to some parts a considerable amount of new matter has been contributed by Mr. Groves in the description of recent experiments, as in Dr. Frankland's work on the luminosity of flames, \&c. The metallurgy of iron, also, which is very fully described, occupies a considerable portion of the part devoted to the consideration of the metals, but not, however, to the exclusion of other important matters connected with these bodies. Mention is also made of the two recently-discovered metals gallium and davium.

Competing as this work must necessarily do with other large and recently written tex!-books, we should have liked to see a little freshening-up given to some of the diagrams, the apparatus in some of the illustrations appearing of rather an antiquated form. As an illustration of this point we might give the diagram illustrating the manufacture of sulphuric acid on the small scale, as shown in Fig. 322. A considerable improvement in the letter-press has, however, been introduced by printing the headings of the paragraphs in larger type than has hitherto been used; this, combined with the references to the original papers from which the information contained in the work has been taken, will, we think, prove of great value to the more advanced student.

The work throughout bears evidence of thorough as well as careful selection in regard to the new material introduced, and we think the publishers are to be congratulated on obtaining the services of such a conscientious worker as $\mathrm{Mr}$. Groves for the revision of this standard text-book.

\section{OUR BOOK SHELF}

A Glossary of Biological, Anatomical, and Physiological Forms. By Thomas Dunman. (London: Griffith and Farran, 1878.$)$

MR. DUNMAN'S glossary is the result of an attempt " to place before the student the pronunciation, derivation, and definition" of the terms "usually employed in that department of biological science which treats of animal life, as set forth in standard text-books of Huxley, Carpenter, Foster, Flower, and others," and will be a useful book, no doubt-the more so as there is no other work covering exactly the same ground. At the same time the derivations and definitions appended to the terms are not always quite correctly given, particularly as regards the zoological terms. The order of birds called "Dromæognathæ" was so named by Prof. Huxley because the Tinamous which compose it have the palate formed like that of the ostriches (Dromcus, an Emeu)not from the Greek "dromaios" directly. "Holothuridea" is from Holothourion-a good Greek Aristotelian word-and has certainly nothing to do with "thuris," a little door, as Mr. Dunman would have us believe. A more probable derivation is $\theta$ ov $\rho \imath$ s, furiosus, because the Holothuria burst in pieces when touched. There are no

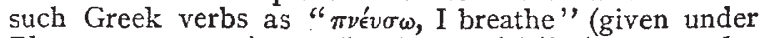
Pharyngnopneusta), or " $\pi \tau$ ó $\omega$, I fall" (given under ptosis). The correct Greek derivations in these cases are $\pi \nu \epsilon^{\prime} \omega$ and $\pi i \pi \tau \omega$. "Egesta" is not formed from "egestio -getting-rid-of," but is simply the participle of egero, meaning such things as are got rid of. Nor are Mr. Dunman's explanations of the purely anatomical terms always faultless, although there is less occasion for criticism here. "The "ligamentum nuche" is formed of elastic not of "connective" tissue. The "sectorial" tooth of the dog is certainly not definable as the fourth premolar, for the dog has no fourth premolar. The "tri- 